Kimmo Murto MD FRCPC, Anne C.P. Lui MD FRCPC, Nicholas Cicutti PhD

\title{
Adding low dose meperidine to spinal lidocaine prolongs post- operative analgesia
}

Purpose: To investigate the effects of the addition of low dose meperidine to spinal lidocaine on the sensory and motor blockade profile, and the quality and duration of postoperative analgesia.

Methods: In a randomized double blind prospective dose finding study 40 patients undergoing transurethral prostatectomy with spinal anesthetic were allocated to receive $75 \mathrm{mg}$ lidocaine $5 \%$ intrathecally as the sole agent (group A), or co-administered with $0.15 \mathrm{mg} \mathrm{kg}^{-1}$ meperidine (group B) or $0.30 \mathrm{mg} \cdot \mathrm{kg}^{-1}$ meperidine (group C). Sensory and motor blockade profiles were documented. Postoperatively, the amount of analgesics required, time to first analgesic, visual analogue scores and adverse events were recorded.

Results: Sensory blocks at or above $T_{10}$ was maintained for 128,156 and 145 minutes in groups $A, B$ and $C$ respectively. There was no difference in the latency or duration of the motor block among the three groups. Patients in group $C$ had lower visual analogue pain scores (VAPS) over time than did those in groups A and B ( $P$ $<0.05$ ). Time to first analgesia was longer ( $429 \pm 197$ minutes) in group $C$ than in group $A$ ( $254 \pm 157$ minutes) $(P<0.05)$. Fewer patients in group $C$ required parenteral opioid postoperatively than in group $A(P<$ 0.05 ). The incidence of bradycardia was higher in the groups receiving meperidine. No symptoms of transient radicular irritation (TRI) were reported in the groups receiving meperidine.

Conclusion: The addition of $0.3 \mathrm{mg} \mathrm{kg}^{-1}$ of meperidine to spinal lidocaine prolongs postoperative analgesia without delaying discharge from post anesthetic care unit (Table II) and reduces the requirement for parenteral analgesics (Table III).

Objectif : Analyser les effets de l'addition d'une faible dose de mépéridine à de la lidocainne intrarachidienne sur le profil du blocage sensitif et moteur et sur la qualité et la durée de l'analgésie postopératoire.

Méthode : Dans une étude randomisée, prospective et en double aveugle pour déterminer une dose, 40 patients admis pour une prostatectomie transurétrale, avec anesthésique intrarachidien, ont été répartis en trois groupes et ont reçu : $75 \mathrm{mg}$ de lidocaine intrathécale $5 \%$ comme seul agent $(A)$, ou avec l'administration de $0,15 \mathrm{mg} \cdot \mathrm{kg}^{-1}$ de mépéridine (B) ou $0.30 \mathrm{mg} \cdot \mathrm{kg}^{-1}$ mépéridine (C). On a documenté les profils de blocage sensitif et moteur. On a enregistré, après l'opération, la quantité d'analgésique nécessaire, le moment de la première analgésie, les scores de l'échelle visuelle analogue et les effets secondaires.

Résultats : Les blocs sensitifs à $T_{10}$ ou plus haut ont été maintenus pendant 128, 156 et 145 min dans les groupes $A, B$ et $C$ respectivement. II n'y a pas eu de différence intergroupe de latence ou de durée du bloc moteur. Les patients du groupe $C$ ont présenté, en fonction du temps, des scores de douleur plus bas à l'échelle visuelle analogue (SDVA) que ceux des groupes $A$ et $B, P<0,05)$. Le temps précédant la première analgésie a été plus long ( $429 \pm 197$ minutes) dans le groupe $C$ que dans le groupe $A(254 \pm 157$ minutes) $(P<0,05)$. Moins de patients du group $C$ ont eu besoin d'opioïdes parentéraux postopératoires que ceux du groupe $A, P<$ 0,05 ). Dans les groupes qui ont reçu de la mépéridine, l'incidence de bradycardie a été plus élevée et aucun symptôme d'irritation radiculaire transitoire (IRT) r'ont été rapportés.

Conclusion : L'addition de $0,3 \mathrm{mg} \cdot \mathrm{kg}^{-1}$ de mépéridine à de la lidocaïne intrarachidienne prolonge l'analgésie postopératoire sans retarder la sortie de la salle de réveil (Table II) et réduit la demande d'analgésiques parentéraux (Table III).

From the Department of Anesthesia, Ottawa Hospital (Civic site), 1053 Carling Ave, Ottawa, Ontario, KIY 4E9 Canada. Address correspondence to: Dr. Kimmo Murto, Department of Anesthesia, Children's Hospital of Eastern Ontario, 401 Smyth Road, Ottawa, Ontario, K1H 8L1. Phone: 613-737-2431; Fax: 613-738-4815.

Accepted for publication January 12, 1999 
I NTRATHECAL meperidine is a unique opioid that not only provides analgesia, but also blocks nerve conduction at the proximal end of the dorsal $\operatorname{root}^{1}$ by a mechanism other than sodium channel blockade. ${ }^{2}$ The nerve conduction blockade is not naloxone reversible. ${ }^{1}$ The analgesic effects of intrathecal meperidine last about six hours. ${ }^{3,4}$ The high lipid solubility of meperidine minimizes rostral spread and, therefore it does not share the intrathecal morphine effects of delayed depression of central respiratory drive. Respiratory depression is a rare observation and usually occurs within one hour of neuraxial meperidine injection when peak cerebral spinal fluid meperidine concentration occurs. ${ }^{5,6}$ Absorption systemically or through the epidural venous plexus is another pathway by which this may take place. Patients are still routinely monitored in the operating room or in the post anesthetic care unit during this period. Most of the literature supports the safety of meperidine and the associated low systemic concentrations when it is administered neuraxially. Meperidine is typically used as the sole spinal agent at doses of $0.5-1.0 \mathrm{mg} \cdot \mathrm{kg}^{-1}$. However, these doses are associated with a high incidence of severe pruritus, nausea and sedation. Combinations of meperidine with bupivacaine have also been reported. Meperidine, when used alone or in combination with bupivacaine, has no intra-operative advantage over bupivacaine. ${ }^{7}$ On the other hand, the addition of meperidine to bupivacaine produces a dose dependent increase in the duration and quality of postoperative analgesia. There are very few reports on the use of combinations of meperidine and lidocaine for spinal anesthesia. ${ }^{8}$

The onset and duration profile of spinal lidocaine provided the best fit for the intraoperative duration of transurethral prostatectomy $(30-90 \mathrm{~min})$ but without any benefit of residual analgesia. One of many challenges in anesthesia is to match an anesthetic regimen that expedites patient recovery and minimizes the nursing burden of a particular operation. To achieve this goal in transurethral prostatectomy, the present study was aimed to provide spinal analgesia with the shortest duration of motor block, and sufficient intrathecal analgesia to allow patients to progress rapidly to oral analgesics without intensive monitoring for respiratory depression. The discharge criterion from PACU for patients with spinal anesthesia at our institution requires resolution of motor block. Hence a combination that minimizes the duration of motor block is important to ensure efficient turnover of patients in the PACU.

No study has examined the addition of low dose meperidine to spinal lidocaine. Accordingly, we designed the present dose finding study to examine the analgesic efficacy of low dose intrathecal meperidine in combination with spinal lidocaine for patients undergoing transurethral prostatectomy.

\section{Materials and methods \\ Patient selection}

Forty elderly ASA 1-3 patients scheduled for endoscopic surgery of the prostate were included in this randomized double blind study after informed consent and ethics committee approval. Patients were allocated according to a computer generated randomization schedule into three groups: A ( $n=13), B$ $(\mathrm{n}=14)$ and $C(\mathrm{n}=13)$. All groups received $75 \mathrm{mg}$ intrathecal hyperbaric lidocaine $5 \%$. In addition, group $B$ received $0.15 \mathrm{mg} \cdot \mathrm{kg}^{-1}$, and group $\mathrm{C} 0.30 \mathrm{mg} \cdot \mathrm{kg}^{-1}$, intrathecal meperidine concomitantly.

\section{Anesthetic techniques}

The attending anesthesiologist had the choice of premedicating the patient with 0.05 to $0.15 \mathrm{mg} \cdot \mathrm{kg}^{-1}$ of diazepam $90 \mathrm{~min}$ before surgery or of administering midazolam at their discretion in the operating room. Once monitors were applied and intravenous access achieved, the lumbar area was aseptically prepared and draped with the patient in the sitting position. A \# 22 to \# 27 gauge Quinckie spinal needle was used to perform the lumbar puncture at the $\mathrm{L}_{2-3}$ or $\mathrm{L}_{3-4}$ interspace. The study solution was injected intrathecally over five seconds. Following injection, the patient was immediately placed in the lithotomy position. Surgery proceeded when a sensory level greater than $T_{10}$ was achieved. If the sensory block did not rise above $\mathrm{T}_{10}$ after $10 \mathrm{~min}$, then failure of spinal anesthetic was recorded and the anesthesiologist proceeded with his/her anesthetic of choice. The maintenance and administration of fluids, oxygen, ephedrine, phenylephrine, atropine, dimenhydrinate and diphenhydramine were given as deemed appropriate by the attending anesthesiologist. No opioids were to be administered intra-operatively. At the end of surgery, the patient was transferred to the post-anesthetic care unit. Postoperative analgesics were at the discretion of attending anesthesiologist and surgeon, and were to be administered only on request.

\section{Clinical monitoring and epaluation criteria}

The attending anesthesiologist and the nurse assessing the patient after surgery were blinded to the group assignments. All patients were monitored with an automatic non-invasive blood pressure device, oxygen saturation monitor and 3- or 5-lead ECG. Sensory block was assessed by pin prick using a blunted Bayer 27 gauge dental needle. Motor block was assessed using 
the Bromage scale: $0=$ no impairment of motor function of feet or legs, 1 = barely able to flex knees, no impairment of feet, 2 = unable to flex knees and barely able to move feet, $3=$ unable to move feet or legs. The patient was instructed to complete a visual analogue score (VAS) rating their level of discomfort every hour for eight hours postoperatively. After $24 \mathrm{hr}$, a blinded observer recorded the VAPS, postoperative analgesic requirements and any adverse events and intervention.

We estimated approximately a $\mathbf{5 0 \%}$ reduction in the mean VAPS in group $C$ relative to groups $A$ and $B$ over the initial $24 \mathrm{hr}$ after surgery. Assuming an $\alpha$ of .05 and ( $1-\beta)$ of $0.8,39$ patients ( 13 per group) were required at the stated level of statistical confidence. Patient demographic data, sensory and motor block onset and duration as well as time to discharge from PACU were analyzed using analysis of variance (ANOVA). Analgesic consumption was analyzed either with ANOVA or contingency tables when data were expressed as proportions. Visual analog pain scores over time were analyzed using repeated measures ANOVA with selected linear pair-wise contrasts, when appropriate. Ordinal data such as sensory block height and the degree of motor block over time were analyzed using the non-parametric Friedman's test and non-parametric version of the Student-NewmanKeuls test for multiple comparisons.

\section{Results}

Of the 40 patients enrolled in the study, none were withdrawn. All of the patients underwent a transurethral resection of the prostate (TURP). The three groups were similar in age, height, weight, and duration of surgery (Table I).

\section{Sensory block}

Sensory block of $T_{10}$ was achieved in all three groups by five minutes after injection of the intrathecal solution. $\mathrm{A} \mathrm{T}_{5}$ sensory blockade occurred in all groups by 20-25 min after injection (Figure 1). Maximum sensory levels of $\mathrm{C}_{8}$ (two patients), and $\mathrm{T}_{1}$ (two patients) were reported in both groups $\mathrm{A}$ and $\mathrm{C}$.

Sensory block at or above $\mathrm{T}_{10}$ was maintained for 128, 156 and $145 \mathrm{~min}$ in Groups A, B and C respectively (Figure 1 ). The times to two segment regression was not different among the three groups (Table II).

\section{Motor block}

There was no difference in latency or duration of the motor block among the three groups: The percentage of patients who achieved Bromage 3 motor block was $100 \%$ in group A, $93 \%$ in group B and $82 \%$ in group
C (Figure 2). There was no difference among the three groups in the density of the block.

\section{Analgesia}

There were no block failures in the three groups. Five patients required intravenous medication for intraoperative discomfort. Two patients in group A received propofol at approximately $100 \mathrm{~min}$ after injection, and required 0.3 and $0.75 \mathrm{mg} \cdot \mathrm{kg}^{-1}$ as single doses for discomfort from bladder distension. One patient in group $B$ required $1 \mathrm{mg} \cdot \mathrm{kg}^{-1}$ propofol $15 \mathrm{~min}$ after spinal injection, but the surgery was completed without any additional sedation. Two patients in group $\mathrm{C}$ required single propofol doses of $0.5 \mathrm{mg} \cdot \mathrm{kg}^{-1}$ and $0.9 \mathrm{mg} \cdot \mathrm{kg}^{-1}$ respectively, within $30 \mathrm{~min}$ of injection of the intrathecal solution for lower abdominal discomfort and anxiety, respectively. One patient of the two patients in group C also received $0.6 \mu \mathrm{gg} \cdot \mathrm{kg}^{-1}$ fentanyl. Both were able to complete the surgery without additional supplements.

The visual analogue pain scores (VAPS $0-100$ $\mathrm{mm}$ ) were different in group $\mathrm{C}$ than in groups $\mathrm{A}$ and $B$ over time (Figure 3 ). Group $C$ maintained a VAPS of $2.5 \mathrm{~mm}$ for three hours after spinal injection. After $24 \mathrm{hr}$ there were no differences among the three groups. The time to first postoperative analgesia ( $p 0$, $p r, i v, i m)$ was different only between groups $\mathrm{A}$ and $\mathrm{C}$.

TABLE I Patient demographic data

\begin{tabular}{lllll}
\hline Group & Age & Height & Weight & $\begin{array}{l}\text { Duration of } \\
\text { surgery } \\
(\text { min })\end{array}$ \\
\hline & $(y r)$ & $(\mathrm{cm})$ & $(\mathrm{Kg})$ & $40.8 \pm 22.6$ \\
\hline $\mathrm{A}(\mathrm{n}=13)$ & $69.2 \pm 6.5$ & $173 \pm 8.3$ & $81.6 \pm 11.8$ & $40.8 \pm 12.2$ \\
$\mathrm{~B}(\mathrm{n}=14)$ & $68.7 \pm 9.4$ & $177 \pm 5.4$ & $82.0 \pm 12.2$ & $40.2 \pm 20.2$ \\
$\mathrm{C}(\mathrm{n}=13)$ & $64.2 \pm 8.8$ & $175.1 \pm 64$ & $77.3 \pm 8.0$ & $36.1 \pm 16.2$ \\
\hline
\end{tabular}

Values are in mean $\pm S D$

TABLE II Sensory and motor block onset and duration (min)

\begin{tabular}{lccc}
\hline Group & $\begin{array}{c}A \\
(n=13)\end{array}$ & $\begin{array}{c}B \\
(n=14)\end{array}$ & $\begin{array}{c}C \\
(n=13)\end{array}$ \\
\hline $\begin{array}{l}\text { Sensory block } \\
\text { Duration of } \mathrm{T}_{10}\end{array}$ & $128 \pm 35.2$ & $156.3 \pm 51.3$ & $144.8 \pm 36.7$ \\
$\begin{array}{l}\text { Time to two } \\
\text { segment regression }\end{array}$ & $86 \pm 31.8$ & $102.6 \pm 28$ & $95.5 \pm 19.1$ \\
$\begin{array}{l}\text { Time to total } \\
\text { regression }\end{array}$ & $184.9 \pm 39$ & $232.1 \pm 64.6$ & $212.2 \pm 47$ \\
$\begin{array}{l}\text { Motor block } \\
\text { Onset time }\end{array}$ & $3.9 \pm 3.3$ & $4.1 \pm 2.6$ & $4.4 \pm 4.6$ \\
$\begin{array}{l}\text { Duration } \\
\text { Time to discharge } \\
\text { from PACU }\end{array}$ & $94 \pm 33.8$ & $111 \pm 35$ & $106 \pm 28.8$ \\
\hline
\end{tabular}

Values are mean $\pm \mathrm{SD}$ 
TABLE III Post operative analgesic consumption over $24 \mathrm{hr}$ per patient

\begin{tabular}{llllll}
\hline Group & $\begin{array}{l}\text { patients not requiring } \\
\text { iv/im }\end{array}$ & $\begin{array}{l}\text { Time to first } \\
\text { analgesia (min) }\end{array}$ & $\begin{array}{l}\text { Equivalent } \\
\text { morphine (mg) }\end{array}$ & $\begin{array}{l}\text { Tylenol \#3 } \\
\text { (\# tablets) }\end{array}$ & $\begin{array}{l}\text { Belladonna/opium suppositories } \\
\text { (\# suppositories) }\end{array}$ \\
\hline A & $6(42 \%)$ & $254 \pm 157$ & $4.46 \pm 5.79$ & $2.6 \pm 2.3$ & $0.3 \pm 0.5$ \\
B & $9(64 \%)$ & $367 \pm 236$ & $5.79 \pm 8.62$ & $1.1 \pm 1.7$ & $0.4 \pm 0.6$ \\
C & $12(92 \%)^{*}$ & $429 \pm 197$ & $0.577 \pm 2.08$ & $2.0 \pm 2.3$ & $1.1 \pm 1.4 \dagger$ \\
\hline
\end{tabular}

Values are mean $\pm \mathrm{SD}$

* $P=0.04$ group $C$ compared to Group A

$\dagger$ two patients in Group $\mathrm{C}$ received B\&O q6h straight per surgeon's request

Postoperative analgesia consumption was calculated after converting $i m$ meperidine to equivalent dose of $i p$ morphine $(1 \mathrm{mg}$ morphine $=10 \mathrm{mg}$ meperidine) (Table III). Two patients in group A received 75 and $50 \mu \mathrm{g}$ fentanyl, respectively. In patients who received $i p$ or im opioids, there was no difference in the amount of opioids administered per patient in the three groups. Interestingly, 12 out of 13 patients $(92 \%)$ in group C did not require any iv or im opioids after surgery, compared with $9 / 14(64 \%)$ in group B and $6 / 13(46 \%)$ in group $A$. There was a statistically significant difference only between groups $\mathrm{C}$ and $\mathrm{A}$. Tylenol \#3 consumption did not differ among the three groups. In addition, a total of four tablets of plain Tylenol $325 \mathrm{mg}$ in each of groups A and B was consumed.

\section{Hemodynamic effects}

Seven patients had transient episodes of sinus bradycardia, defined as heart rate of $<50 \mathrm{bpm}$. Six of these were in group $\mathrm{C}$, one of whom had a heart rate of 25 $\mathrm{bpm}$. One patient in group B had a heart rate of 48 bpm. These bradycardic episodes occurred at a mean of 44 (range 28 to $60 \mathrm{~min}$ ) after spinal injection. All the episodes responded to $0.6 \mathrm{mg}$ atropine $i v$ and/or $5 \mathrm{mg}$ ephedrine $i v$. There was no bradycardia recorded in group A.

Thirteen patients had transient episodes of hypotension, defined as decrease in blood pressure requiring treatment by attending anesthesiologist. The episodes occurred between 20 and $60 \mathrm{~min}$ after spinal injection and were evenly distributed among the three groups. The events were not associated with bradycardia except for two patients in group C. All responded to either a fluid bolus and/or 5-10 mg ephedrine $i v$.

\section{Time to discharge from recovery room}

There were no differences in times to discharge from the post anesthetic care unit (PACU) among the three groups (Table II).

\section{Complications}

No episodes of hypoxemia resulting in oxygen saturation $<90 \%$ occurred in the intraoperative or recovery room period. At the $24 \mathrm{hr}$ follow up, there were no episodes of apnea resulting in cardiac arrest in any patients. Nausea was reported in two patients in group $\mathrm{C}$ and one patient in group $\mathrm{B}$. One $82 \mathrm{yr}$ old patient complained of a postoperative headache which resolved spontaneously without intervention. One patient in group A had pruritus. This same patient also complained of back pain and spasm approximately 12 $\mathrm{hr}$ following an unremarkable spinal anesthetic using a 26 gauge Quincke needle at the level of the $L_{2-3}$ interspace. He had no history of previous back problems. The symptoms spontaneously resolved by $24 \mathrm{hr}$. All the patients were catheterized, therefore urinary retention was not assessed.

\section{Discussion}

This study showed that the addition of $0.30 \mathrm{mg} \cdot \mathrm{kg}^{-1}$ of meperidine to spinal lidocaine 5\% (group C) prolonged postoperative analgesia compared with spinal lidocaine $5 \%$ without meperidine (group A). The increase in duration of analgesia was not accompanied by an increase in the duration of sensory or motor blockade. More patients $(92 \%)$ in group $\mathrm{C}$ did not require iv or im opioids for analgesia postoperatively than in group $\mathrm{A}(46 \%)$. The administration of intrathecal meperidine was associated with a higher incidence of bradycardia. One patient in group A reported symptoms of TRI. There were no reports of TRI in the groups receiving meperidine.

The co-administration of $0.15-0.30 \mathrm{mg} \cdot \mathrm{kg}^{-1}$ meperidine and lidocaine $5 \%$ intrathecally has not been evaluated previously. This study reports the effects of the addition of low dose meperidine to spinal lidocaine on the sensory and motor blockade profile, quality and duration of postoperative analgesia as well as adverse effects.

There was no difference in the onset and duration of sensory and motor block in the three groups. 


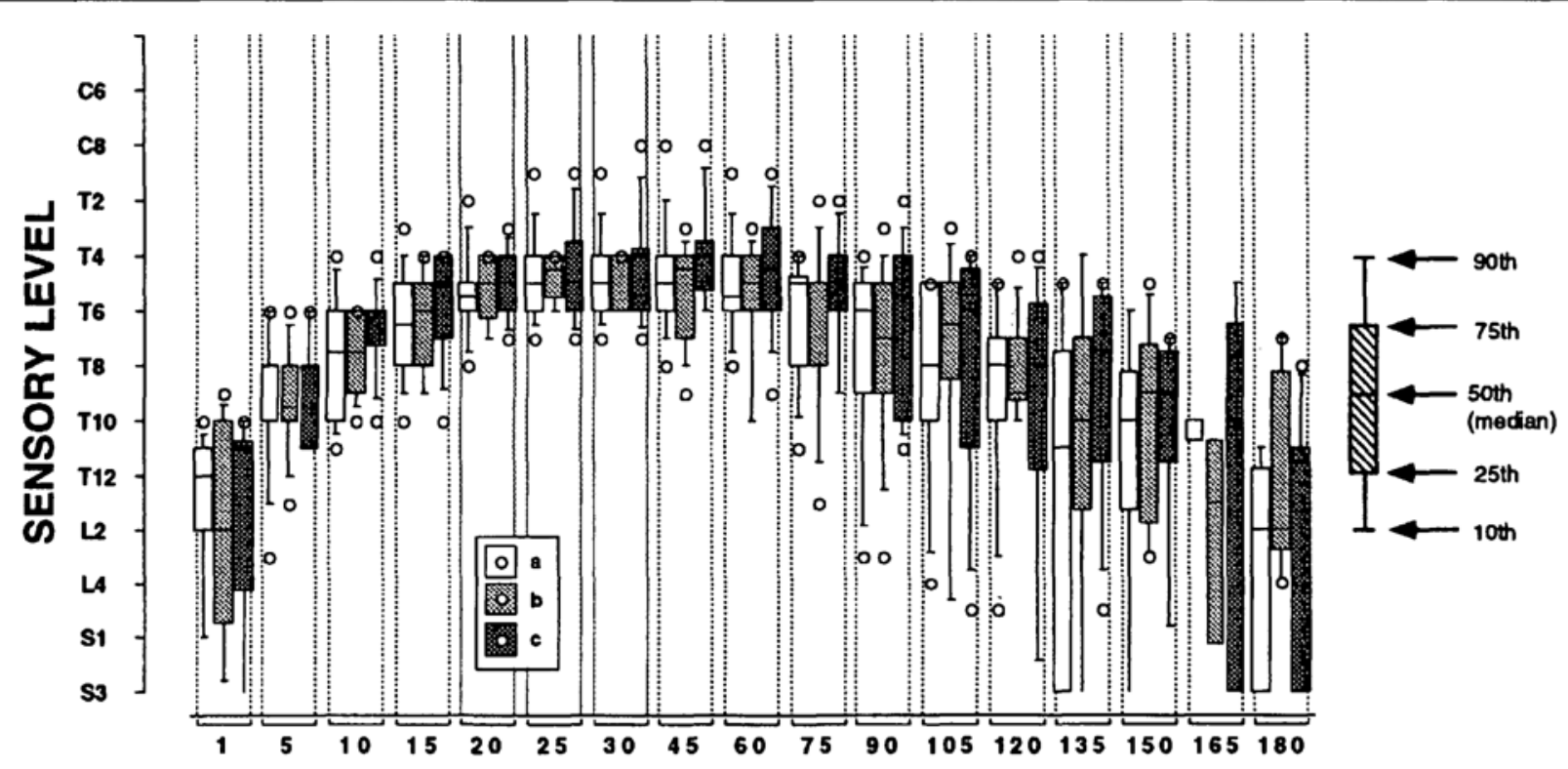

TIME (min)

FIGURE 1 Box Plot which displays sensory block levels for the three groups. Values depicted represent the 10th, 25th, 50th, 75th and 90 th percentiles; i.e., they illustrate their relative distributions. Values above the 90 th, and below the 10th percentile are plotted scparately, conveying information regarding the outliers. There was no significant difference among the groups over time.

Likewise, the duration of surgical analgesia (defined as block height greater than $T_{10}$ ) was similar in the three groups. The addition of prilocaine to meperidine spinal anesthetic was found to improve motor and sensory block. ${ }^{9}$ When $18 \mathrm{mg}$ meperidine was added prior to induction with lidocaine for continuous spinal anesthesia, the dose of lidocaine required to achieve an $\mathrm{L}_{2}$ sensory block was reduced by $35 \%{ }^{9}$ suggesting synergistic effects. There was no synergism found in this study. Unlike most opioids, intrathecal meperidine can be used alone for surgical analgesia with apparent local anesthetic properties. More recent studies on the peripheral nerve block suggests mechanisms of action other than sodium channel inhibition. ${ }^{2}$

The present study showed that the addition of 0.3 $\mathrm{mg} \cdot \mathrm{kg}^{-1}$ meperidine to spinal lidocaine delayed the time to first analgesia to 4 - $10 \mathrm{hr}$ compared with plain lidocaine. Previous studies using combinations of hyperbaric prilocaine ${ }^{9}$ hyperbaric bupivacaine $0.5 \%^{3}$ and isobaric lidocaine $1.6 \%^{9}$ combined intrathecally with meperidine found that meperidine improved the quality and duration of postoperative analgesia. The addition of $0.3 \mathrm{mg} \cdot \mathrm{kg}^{-1}$ meperidine is similar to the duration of analgesia $(447.6 \pm 184.0 \mathrm{~min})$ provided by a single intrathecal dose of $60 \mathrm{mg}$ of meperidine. ${ }^{4}$ This is consistent with the pharmacokinetic behaviour of intrathecal meperidine with a cerebrospinal fluid half life of $6.0 \mathrm{hr} .^{10}$

It is of interest to note the higher incidence of bradycardia in patients receiving co-administration of intrathecal meperidine. Whether this is a systemic effect involving direct increase in vagal activity, or reflects a high sympathetic block is unclear from this study. To infer that sympathetic block height is higher in the same patients receiving meperidine that have similar levels of sensory block is difficult to explain. Maurette et al..$^{8}$ found that the addition of meperidine to spinal lidocaine increases the incidence of hypotension requiring treatment with ephedrine suggesting increased sympathetic blockade. In our study, there was no difference in the occurrence of hypotension among the three groups. The higher dose of lidocaine and a higher resultant block height may have resulted in a higher incidence of hypotension in the lidocaine only group, thus obscuring the effects of the addition of meperidine.

The incidence of bradycardia was $46 \%(6 / 13)$ and occurred in the group receiving $0.3 \mathrm{mg} \cdot \mathrm{kg}^{-1}$ meperidine, which was much higher than the $13 \%$ that occurred with spinal anesthesia. ${ }^{11}$ These bradycardic events responded readily to single doses of atropine or ephedrine without further adverse effects. Hypotension 
a)

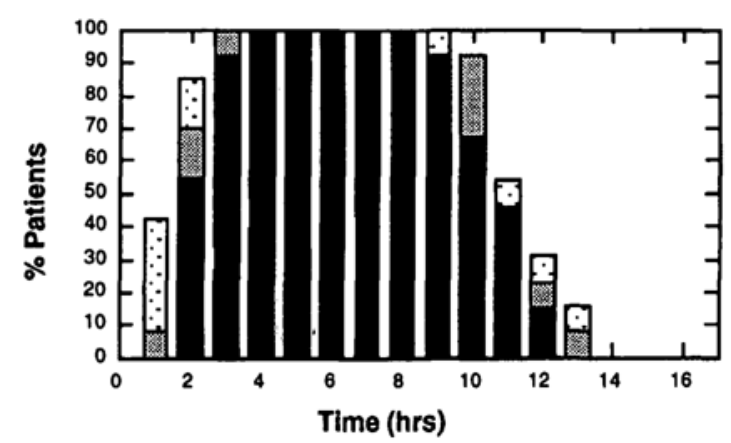

b)

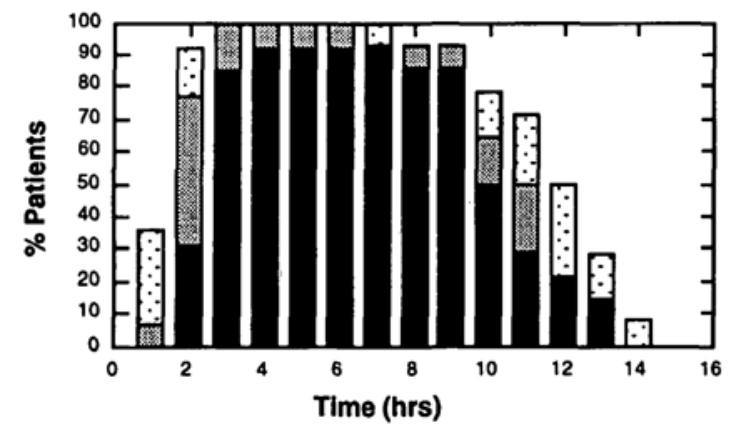

c)

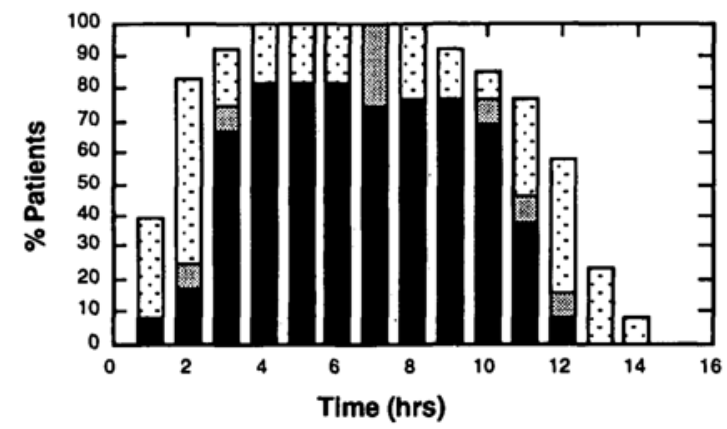

FIGURE 2 Composite stacked bar graph illustrating the percentage of patients over time (hours) with Bromage score of 1 (sparse dots), 2 (dense dots), 3 (solid bars). Percentage of patients with Bromage 3 block was depicted (100\% in a, $93 \%$ in b and $82 \%$ in c). These differences were not statistically significant. Figures $2 a, 2 b$, and $2 c$ correspond to groups $A, B$ and $C$ respectively.

or bradycardia occurred 30 to 60 min after injection of spinal anesthetic, similar to the findings reported by Carpenter et al..$^{11}$ The incidence of bradycardia associated with intrathecal meperidine in other reports ranged from 0 to $43 \% .^{12}$

The addition of low dose meperidine to spinal lidocaine did not appear to increase the occurrence of nausea and vomiting, pruritus, respiratory depression or post dural puncture headache. Of interest is the apparent absence of transient radicular irritation (TRI) in the two groups of patients $(n=27)$ receiving spinal meperi-

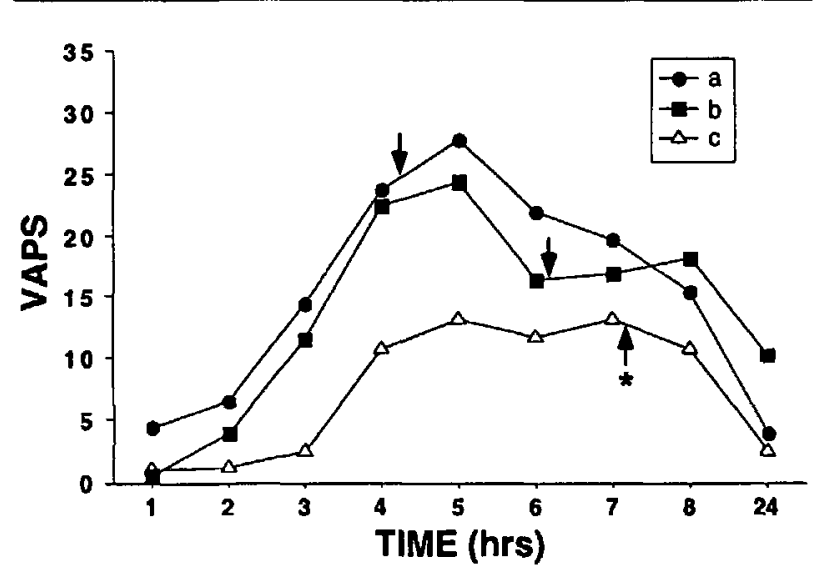

FIGURE 3 Graphical representation of mean visual analog pain scores (VAPS) for the 3 groups over time. A statistically significant difference $(P<0.05)$ over time was revealed when comparing group $C$ relative to groups $A$ and $B$. Arrows indicate times to first analgesia. The asterisk indicates the statistical significance $(P<$ 0.05 ) in time to first analgesia when comparing group $C$ with group A.

dine. Although the numbers were small, using the approach by Sacket et al., ${ }^{13}$ the incidence might be predicted to be approximately $4 \%$ with $95 \%$ confidence, suggesting, a much lower incidence of TRI than the 16$37 \%$ reported. ${ }^{14,15}$ This suggests that the addition of meperidine to spinal lidocaine may confer 1 ) neuroprotection; or 2) pre-emptive analgesia that prevents manifestation of dysesthesia 12 to $24 \mathrm{hr}$ following spinal anesthetic; or 3) antagonism of lidocaine including the TRI effects. The authors favour the mechanism of preemptive analgesia as the most likely cause of decreased symptoms. Although neurotoxicity is most commonly associated with spinal lidocaine, neurological complications following spinal tetracaine, ${ }^{16}$ bupivacaine ${ }^{17}$ and the addition of phenylephrine ${ }^{18}$ have also been reported. Dahlgren ${ }^{19}$ countered that, rather than neurotoxicity, inflammatory activity in the meninges may be the etiological factor in TRI. Recent controversy about the neurotoxicity of lidocaine have led to a decline in its popularity. Yet, lidocaine remains a safe and clinically useful spinal drug ${ }^{20}$ unmatched in its rapid onset and short duration that suits many surgical procedures lasting about an hour. If the co-administration of meperidine reduces the incidence of TRI as hypothesized in this paper, anesthesiologists' and patients' acceptance for spinal lidocaine may increase.

The methodology employed reflected existing practice in our institution at the time of the study. Thus, the surgical team wrote all postoperative orders. 
Although postoperative analgesia was not standardized, the data on the time to first analgesia and duration of sensory and motor blockade were not affected. We wanted to make the distinction between $i v / i m$ opioids and $p o / p r$ analgesics and we felt that this was a milestone for change in nursing load and home readiness from an analgesic standpoint. The antispasmodic belladonna and opioid ( $\mathrm{B} \& \mathrm{O})$ is commonly used in urological practice: $\mathrm{B} \& \mathrm{O}$ contain $65 \mathrm{mg}$ opium and $15 \mathrm{mg}$ belladonna and was used specifically for bladder spasm. When administered rectally, one $\mathrm{B} \& \mathrm{O}$ translates to $<1 \mathrm{mg}$ iv morphine. The systemic contribution of $\mathrm{B} \& \mathrm{O}$ is minimal, but might have reduced analgesic demand by reducing the discomfort from bladder spasm.

The addition of $0.30 \mathrm{mg} \cdot \mathrm{kg}^{-1}$ meperidine to spinal lidocaine prolonged the time to first analgesia to six hours without prolonging discharge from PACU (Table II). Due to lack of standardization in postoperative analgesic therapy, overall $24 \mathrm{hr}$ analgesia must be interpreted with caution. Repeated measures analysis revealed that the VAPS over time ( $24 \mathrm{hr}$ ) in group C was different from that of the other two groups. Furthermore, this lower pain score is associated with an eight-fold reduction in iv/im opioid requirement, as well as $50 \%$ fewer patients requiring iv or $i m$ opioids, compared with group A. Ninety two percent of patients receiving this combination progressed to Tylenol\#3 and $\mathrm{B} \& \mathrm{O}$ suppositories without requiring iv or $i m$ opioids. A reduction in the nursing workload and cost associated with the administration of parenteral drugs was implied. This combination provided a short duration of motor blockade with extended analgesia that matched well for an efficient postoperative recovery from transurethral prostatectomy. The addition of 0.15 $\mathrm{mg} \cdot \mathrm{kg}^{-1}$ meperidine to spinal lidocaine did not prolong analgesia time nor reduce the number of patients requiring parenteral opioids. The main side effect of the addition of meperidine is an increased incidence of bradycardia that readily responded to atropine and/or ephedrine. It is, nonetheless, prudent to avoid this combination in patients with a history of brady-arrhythmias or rate-dependent cardiac output. Further studies are required to demonstrate the reduction in the incidence of lidocaine induced TRI with the addition of intrathecal meperidine.

\section{Conclusion}

This study revealed that the addition of $0.3 \mathrm{mg} \cdot \mathrm{kg}^{-1}$ meperidine to spinal lidocaine prolonged analgesia without prolonging sensory or motor blockade and discharge from the post-anesthetic care unit. Ninety two percent of the patients receiving this combination pro- gressed to oral analgesics only without requiring any iv/im opioids. The addition of $0.15 \mathrm{mg} \cdot \mathrm{kg}^{-1}$ meperidine to spinal lidocaine did not confer any analgesic advantage. Careful monitoring for bradycardia and hypotension is recommended as for all spinal anesthetics.

\section{Acknowledgments}

We wish to thank Mary Lou Crossan MLT and Patrice Lindsay RN MED for their technical assistance.

\section{References}

1 Jaffe RA, Rowe MA. Comparison of the local anesthetic effects of meperidine, fentanyl, and sufentanil on dorsal root axons. Anesth Analg 1996; 83: 776-81.

2 Flanagan MT, Walker FO, Butterworth J. Failure of meperidine to anesthetize human median nerve. A blinded comparison with lidocaine and saline. Reg Anesth 1997; 22: 73-9.

3 Nguyen Thi TV, Orliaguet G, Liu N, Delaunay L, Bonnet $F$. A dose-range study of intrathecal meperidine combined with bupivacaine. Acta Anaesthesiol Scand 1992; 36: 516-8.

4 Norris $M C$, Honet JE, Leighton BL, Arkoosh VA. A comparison of meperidine and lidocaine for spinal anesthesia for postpartum tubal ligation. Reg Anesth 1996; 21: 84-8.

5 Maurette P, Tauzin-Fin P, Vinfon G, Brachet-Lierman $A$. Arterial and ventricular CSF pharmacokinetics after intrathecal meperidine in humans. Anesthesiology 1989; 70: 961-6.

6 Ong B, Segstro R. Respiratory depression associated with meperidine spinal anaesthesia. Can J Anaesth 1994; 41: 725-7.

7 Conway F, Critchley LAH, Stuart JC, Freebairn RC. A comparison of the haemodynamic effects of intrathecal meperidine, meperidine-bupivacaine mixture and hyperbaric bupivacaine. Can J Anaesth 1996; 43: 23-9.

8 Maurette P, Bonada G, Djiane V, Erny P. A comparison between lidocaine alone and lidocaine with meperidine for continuous spinal anesthesia. Reg Anesth 1993; 18 : 290-5.

9 Tauzin-Fin P, Maurette P, Vinfon G, Hecquet D, Houdet $M-C$, Bonnet $F$. Clinical and pharmacokinetic aspects of the combination of meperidine and prilocaine for spinal anaesthesia. Can J Anaesth 1992; 39: 655-60.

10 Nordberg G, Hansdottir V, Bondesson U, Boréus LO, Mellstrand T, Hedner T. CSF and plasma pharmacokinetics of pethidine and norpethidine in man after epidural and intrathecal administration of pethidine. Eur J Clin Pharmacol 1988; 34: 625-31.

11 Carpenter RL, Caplan RA, Brown DL, Stephenson C, $W u R$. Incidence and risk factors for side effects of spinal anesthesia. Anesthesiology 1992; 76: 906-16. 
12 Ngan Kee WD. Intrathecal pethidine: pharmacology and clinical applications. Anaesth Intensive Care 1998; 26: 137-46.

13 Sackett DL, Haynes RB, Gent M, Taylor DW. Compliance. In: Inmen WHW (Ed.). Monitoring for Drug Safety. Lancaster: MTP, 1980.

14 Hampl KF, Schneider MC, Ummenbofer W, Drewe J. Transient neurologic symptoms after spinal anesthesia. Anesth Analg 1995; 81: 1148-53.

15 Pollock JE, Neal JM, Stephenson CA, Wiley CE. Prospective study of the incidence of transient radicular irritation in patients undergoing spinal anesthesia. Anesthesiology 1996; 84: 1361-7.

16 Sumi M, Sakura S, Kosaka Y. Intrathecal hyperbaric $0.5 \%$ tetracaine as a possible cause of transient neurologic toxicity. Anesth Analg 1996; 82: 1076-7.

17 Kubina $P$, Gupta A, Oscarsson A, Axelsson $K$, Bengtsson $M$. Two cases of cauda equina syndrome following spinalepidural anesthesia. Reg Anesth 1997; 22: 447-50.

18 Sakura S, Sumi M, Sakaguchi $Y$, Saito $\Upsilon$, Kosaka $Y$, Drasner $K$. The addition of phenylephrine contributes to the development of transient neurologic symptoms after spinal anesthesia with $0.5 \%$ tetracaine. Anesthesiology 1997; 87: 771-8.

19 Dablgren N. Lidocaine toxicity: a technical knock-out below the waist? (Editorial) Acta Anaesthesiol Scand 1998; 42: 389-90.

20 Carpenter $R L$. Hyperbaric lidocaine spinal anesthesia: do we need an alternative? Anesth Analg 1995; 81: 1125-8. 